one-tenth aliquot parts taken. These are heated to $70^{\circ} \mathrm{C}$, about I 5 cc. of I : 4 sulfuric acid added, followed by a decided excess of sodium acid sulfite solution, and the thiocyanate precipitated with a hot ro per cent solution of copper sulfate. After standing ro min. the CuCNS is filtered off through a Gooch crucible, the bottom of which is covered with a circle of filter paper, followed by a layer of paper pulp which is in turn partly covered by a small piece of fiter paper. Too long standing previous to filtering is to be avoided as it increases the tendency of the CuCNS to pass through the filter as a colloid. The impure CuCNS is washed with hot water of about the same temperature as the original solution which was filtered. Since a little $\mathrm{CuCNS}$ sometimes passes through the filter in the colloidal form, the filtrate, if clear, should be removed and discarded as soon as the last of the liquid has been poured through the filter. If a little of the precipitate now passes through the filter upon washing, a quantity of paper pulp may be added to it and the wash water refiltered through an ordinary paper filter, washed with hot water, and combined with the major portion of the CuCNS precipitate.

The residue, consisting chiefly of paper pulp and CuCNS, is treated with $25 \mathrm{cc}$. of $N$ sodium hydroxide, a little bromine water is added to oxidize the copper, and after a few minutes the paper pulp is filtered off and thoroughly washed with hot water. A little more bromine water is added to the alkaline solution and it is digested at the boiling point for one hour. It is made slightiy acid with hydrochloric acid, the bromine boiled off, and the solution taken to dryness. The dry residue is taken up with hot water containing a little $\mathrm{HCl}$ and filtered from silica. The sulfur present originally in the CuCNS is the only sulfur now left in the solution and it is entirely in the form of sulfate. This may now be precipitated with barium chloride and determined in the usual manner and the thiocyanate calculated.

For the purpose of checking the method, the thiocyanate content of the liquor was determined by the above method and also the thiocyanate content of the liquor to which a known amount of potassium thiocyanate had been added. The results indicated that thiocyanate in ammoniacal liquor can be determined by this method to within $0.0 \mathrm{I}$ g. per liter.

Aside from the exercise of a little technique in filtering, the analysis proceeds quite nicely.

\section{VOLUMETRIC METHOD FOR THE DETERMINATION OF DIASTATIC CAPACITY}

By J. T. Flohil

Cerfal Products Companx, Manitowoc, Wisconsin Received Jatiuary 16,1920

$A^{T} 5$ per cent malt solution is prepared according to Lintner. ${ }^{1}$ One cc. of the extract is introduced into Io0 cc. of a 2 per cent soluble starch solution in a 200 cc. flask, left to act for exactly one hour at $20^{\circ} \mathrm{C}$., then treated with ro cc. of 0.1 sodium hydroxide to stop the diastatic action, and diluted with water to the 200 cc. mark.

1Z. prakt. Chem., 1886, 386.
Twenty-five cc. of this solution are transferred to a $300 \mathrm{cc}$. Erlenmeyer flask, exactly io cc. each of Fehling's Solutions I and II added, and the volume brought up to $50 \mathrm{cc}$. with $5 \mathrm{cc}$. water. The mixture is boiled slowly for $2 \mathrm{~min}$, and immediately cooled under the cold water faucet, but not much under $25^{\circ}$. Ten cc. of a 30 per cent potassium iodide solution, or $3 \mathrm{~g}$. potassium iodide and ro $c c$. of a 25 per cent sulfuric acid solution, are added successively and the liberated iodine titrated with a $0.1 N$ thiostilfate solution to a creamy yellow color, the soluble starch present serving as an indicator.

\section{CALCULATION}

Let $p$ cc. be the amount of thiosulfate used in this titration, $n$ cc. the amount of thiosulfate used in a blank test ( $25 \mathrm{cc}$., $5 \mathrm{cc}$. water, $20 \mathrm{cc}$. Fehling's solution); then $n-p=m$ is the amount of thiosulfate equivalent to the copper sulfate reduced by the maltose sugar.

According to Lintner, if $I \mathrm{cc}$. of a 5 per cent malt infusion in $\mathrm{r} 00 \mathrm{cc}$. of 2 per cent starch solution produces just enough maltose to reduce $50 \mathrm{cc}$. of Fehling's solution its strength is $100^{\circ}$. This solution diluted to $200 \mathrm{cc}$. of I per cent starch solution will also reduce 50 cc. of Fehling's solution, and $25 \mathrm{cc}$. will reduce 6.25 cc. of Fehling's solution. We here assume that the quantity of copper sulfate reduced is proportional to the amount of maltose present, without making an appreciable error.

If $20 \mathrm{cc}$. of the Fehling's solution is equivalent to $n$ cc. $0 . \mathrm{I} N$ thiosulfate, then $\mathrm{I}$ cc. is equivalent to $n / 20 \mathrm{cc}$. thiosulfate.

If $25 \mathrm{cc}$. of the solution mentioned in the beginning of this article reduce Fehling's solution equivalent to $6.25 \mathrm{n} / 20 \mathrm{cc}$. of thiosulfate, the Lintner value is $100^{\circ}$.

If $25 \mathrm{cc}$. of the solution reduce Fehling's solution equivalent to $m \mathrm{cc}$. of thiosulfate, its strength is $\frac{m}{\frac{6.25 n}{20}} \times 100=320 \frac{m}{n}$ degrees Lintner.

EXAMPLE--In a blank test the amount of iodine set free by the copper sulfate was equivalent to $27.0 \mathrm{cc}$. o. I $N$ thiosulfate, or $n=27.0$.

In the actual test the amount of iodine set free by the copper sulfate was equivalent to $15.0 \mathrm{cc}$. $0.1 \mathrm{~N}$ thiosulfate; therefore $m=27.0-\mathrm{I} 5.0=12.0$ and the diastatic capacity is $320 \mathrm{I} 2 / 27$ or $142^{\circ}$ Lintner.

\section{THE UNIFORM COMF OSITJON OF COMMERCIAL "STEARIC" AC.DS, AND ITS EXPLANATION By Ben H. Nicolet}

Melion Institute of Industrial Research, Pitrsburgh, Pa. Received October 27, 1919

Sometime ago the writer had occasion to make some comparative tests on a number of samples of commercial stearic acids chosen at random. The titers were surprisingly uniform throughout the series and when these were corrected for the small and varying iodine numbers which the different samples showed, the agreement became startling. The maximum variation in the corrected titers for the six samples; coming from five entirely different sources, was less than $0.5^{\circ}$. 
Such a finding appeared to demand an explanation, and one is here offered, based on the known series of solid solutions formed in mixtures of stearic and palmitic acids.

The results of interest in the present connection are given in Table $\mathrm{I}$. The samples examined may be described as follows:

(1) Domestic, source unknown

(2) "Best," Celina Stearic Acid Company

(3) "Standard," Emery Candle Company

(4) "Double pressed," Rub-No-More Company

(5) "Triple pressed," Rub-No-More Company

(6) "Finest imported," Dutch

Technical stearic acid is produced by successive pressings of fatty acid mixtures which originally have a considerable content of unsaturated fatty acids. At each pressing, a lower melting fraction is removed, and after two or three pressings little of the unsaturated acids remain, as shown by the iodine numbers found.

TABLE I-EXAMINATION OF COMMERCIAI "STEARIC" ACIDS

$\begin{array}{ccccccc}\text { Sample number........... } & 1 & 2 & 3 & 4 & 5 & 6 \\ \text { Iodine number......... } & 1.3 & 1.6 & 8.0 & 4.0 & 1.9 & 2.4\end{array}$

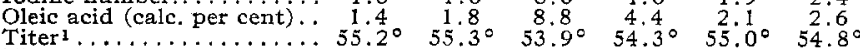
Titer ${ }^{1}$ for zero $\mathrm{I}_{2} \ldots \ldots \ldots$ number

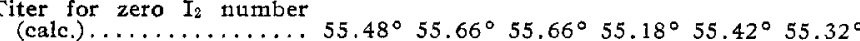

1 The titers calculated for zero jodine number were obtained by adding to the titers found $0.2^{\circ}$ for each per cent oleic acid present. This is an approximately correct allowance for small amounts of oleic acid in any stearic-palmitic acid mixture.

The constancy of the titers given in the last line of the table indicates that the ratio of stearic to palmitic acid approaches a definite value as the pressing is continued.

To explain this it is necessary to refer to the curve showing the solidifying points of the system stearic acid-palmitic acid. De Visser ${ }^{l}$ and Carlinfanti and Levi-Malvano ${ }^{2}$ have drawn such curves and pointed out the relations which they indicate as to the formation of solid solutions. Since titer determinations as ordinarily carried out vary somewhat in principle as well as in practice from the carefully determined solidification points of these authors, a similar curve of titers of mixtures of stearic and palmitic acids is given in the accompanying curve. The values from which this curve is constructed were determined for a different purpose and will be given elsewhere.

From $A$, the titer of pure stearic acid, the curve falls continuously to $B$, then with further addition of palmitic acid rises slightly to a maximum at $\mathrm{C}$ and then falls to D. From D the curve again rises normally to $E$, the titer of pure palmitic acid. The curve is thus divided into sections in which the effect of fractional crystallization, either with or without a solvent, will be very different. The pressing to which the acids are subjected is equivalent to a fractional crystallization.

The general laws describing the behavior of solid solutions indicate that a mixture whose composition was represented by any point between $B$ and $A$ would eventually yield pure stearic acid. Similarly, pure palmitic acid would be the end-product from a mixture lying between $D$ and $E$. On the other hand, a mixture originally represented by a point on the section $\mathrm{BD}$ would approach the composition represented by

\footnotetext{
1 Rec. trav. chim., 17 (1898), 182, 316.
}

2 Gazz, chim. ital., [II] 39 (1909), 368. the maximum at $\mathrm{C}$ and thereafter show no further separation.

The point $C$ represents a palmitic acid content of 55 per cent, and a titer of $55.4^{\circ}$. This appears to be a rather close description of the "stearic" acids examined. Furthermore, their titers are depressed by successive small additions of palmitic acid. A little stearic acid added lowers the titer, and further additions raise it rather rapidly. The acids have all therefore approximately the composition $\mathrm{C}$, which apparently is represented on the curve with a titer a few tenths of a degree too low.

All the samples examined are thus seen to contain palmitic acid to the extent of 52.5 to 55 per cent of their saturated acids. If the explanation here put forward be accepted, it follows that in the material

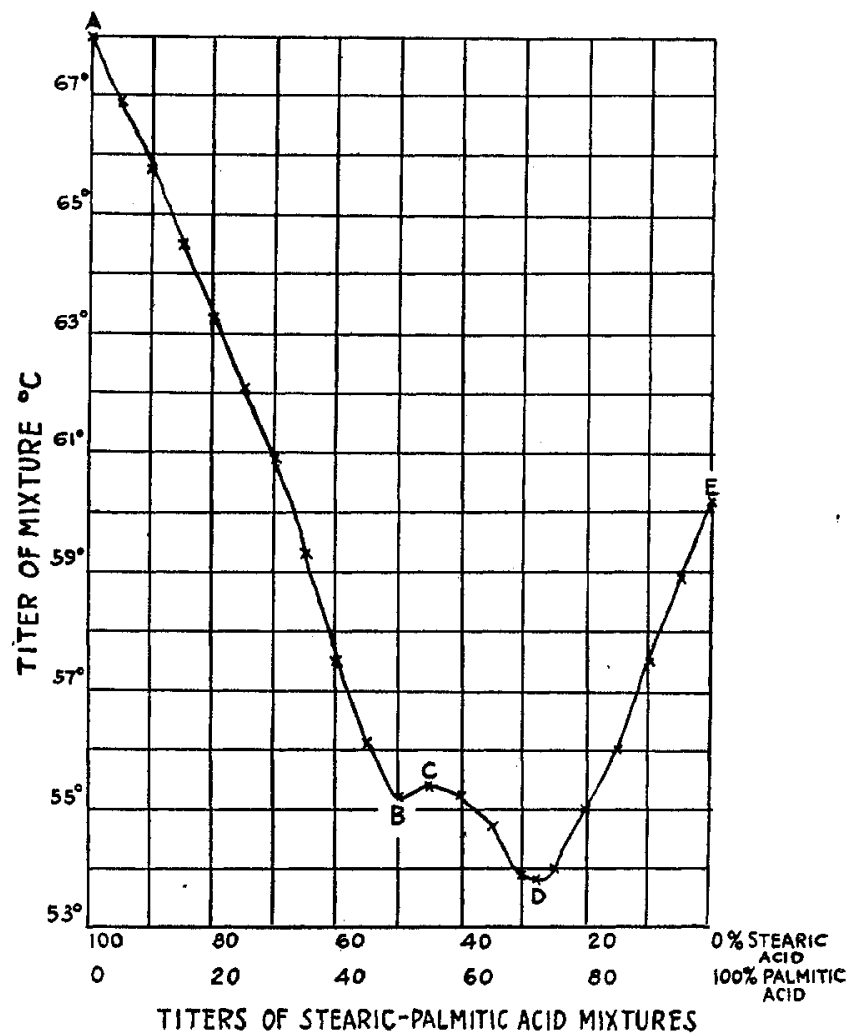

originally subjected to pressing, the saturated acids contained between 50 and 72 per cent palmitic acid.

Very little is actually known as to the ratio of palmitic to stearic acid in fats and oils. Most of the information on the subject in the literature comes from the work of Hehner and Mitchell ${ }^{1}$ on the determination of stearic acid. They report a commercial stearic acid examined by them as having iodine number 2.3 , melting point (not titer) $56.2^{\circ}$, and stearic acid 48.7 per cent (the mean of five determinations varying from 47.0 to 50.6 per cent). In view of the uncertainty of their method, these results do not contradict the conclusions here reached.

\section{SUMMARY}

Attention is called to the remarkable constancy of the ratio of palmitic to stearic acids in a number of technical "stearic" acids.

1 A nalyst, 21 (1896), 316. 
An explanation of this constancy is offered based on the solid solutions formed between these two acids. This requires that "stearic" acids showing this effect should have as their source acid mixtures, the saturated acids of which contain between 53 and 72 per cent of palmitic acid.
As the explanation given must stand or fall with the necessity of the fulfillment of this condition, and as the writer is not sufficiently familiar with the manufacture of "stearic" acid to know whether in general it is fulfilled, discussion on this point is particularly invited.

\section{LABORATORY AND PLANT}

\section{PHOTOBIBLIOGRAPHIC RESEARCH METHODS-THE COMPILATION OF TECHNICAL DATA WITH THE AID OF PHOTOGRAPHY}

\section{By Arthur Worischek}

Patent Department, General Electric Co., Washington, D. C. Received May 11, 1920

The methods employed by professional searchers, compilers and "experts in patent causes," although not yet standardized, have nevertheless been very ably described. ${ }^{1}$

The weakest point in any system of searching and collating technical data is the accurate transcription of tabulated matter and the reproduction of illustrations when these occur in the text. In the author's opinion, it should be possible to copy articles, tables, complicated diagrams and even entire chapters of textbooks by means of some cheap and simple process and without causing annoyance to fellow readers or damage to the books consulted. If a journey to a distant library is necessitated it should be possible to so plan the trip that copies of all the data needed in a given investigation may be brought home in a convenient form. A research worker would then be able to compile his own textbook on any given subject and arrange the subject matter to suit his own particular convenience and needs.

The author having had occasion to undertake extensive research searching during the past few months was struck by the lack of any simple method for copying articles and diagrams. Tedious scribbling appears to be the method exclusively employed, with occasional laborious and time-consuming tracing. A search through the literature revealed a number of attempts along this line, all based upon some adaptation of photography. ${ }^{2}$

Microphotographic copying of printed matter was employed for the transmission of intelligence during the siege of Paris in $1870 .^{3}$ Despatches were printed on a large sheet of paper which was then microphotographically copied onto a film of collodion. According to Tissandier ${ }^{4}$ each page contained some 5,000 letters,

1 A. B. Eason, "Sources of Technical Information," Electrician (Lon.), 82 (1919), 326-7; E. D. Greenman, "Technical Literature and How to Use It," Special Libraries, 9 (1918); 89; H. Hibbert, "The Art of Searching Chemical Literature," Chem. \&o Met. Eng., 20 (1919), 578; W. F. Jacob, "The Technical Library and Its Use," Polytech. Eng., 16 (1916), 36; E. N. Jessop, "German Patent Bibliography," This Journal, 8 (1916), 1053.

2 For an extensive bibliography on the subject of "Photography in Library Work," see G. A. Evers, Maandblad voor Bibliotheekwezen ('sGravenhage), 1 (1913), 10, 225.

2 Dagron, "The Preparation of Microphotographic Despatches on Film," J. Phot. Soc. London, 16 (1871), 102; Brit. J. Phot., 18 (1871), 616. " "History and Handbook of Photography," London. Translated by J. Thomson. Low, Marston, Low and Searle, 1876. "Microscopic Despatc ges during the Siege of Paris," Chap. 6, pp. 234-48. equivalent to 300 despatches, and $r 6$ of these pages were copied onto a collodion film 2 in. long and $\mathrm{I}$ in. wide, weighing less than one grain. These films were transmitted by carrier pigeons and upon arrival at headquarters were placed in a projecting lantern and thrown upon a screen, while a number of copyists or scribes transcribed the despatches.

Fessenden ${ }^{1}$ described a method for photographically compiling his own data collection. His method consisted in copying pages of books onto standard sized plates from which standard sized prints could be made, suitable index numbers being marked upon the film before printing. Other workers have also proposed similar schemes and a method was described in $1909^{2}$ in which the book to be copied was placed upon the floor and copied by means of a camera equipped with a reversing mirror and using bromide paper instead of plates. In the "reflection by contact" or "catatype" method $^{3}$ a sheet of sensitized paper is placed with its sensitive side in contact with the print to be copied, the light being allowed to pass through the paper. The method does not, however, appear to have come into practical use.

J. L. Mauch" has obtained a patent for a "photogenic copying device." He has combined "means for applying a sensitized strip to a surface to be copied with means for projecting light through said strip upon said surface and means to obtain a uniform exposure of said strip." The apparatus is to be held in the hand and "rolled" over the page of a book, etc.; the unexposed sensitive paper being drawn from one spool and the exposed paper wound up on another spool. This, therefore, appears to be a mechanically controlled application of the "reflection by contact", method. A patent by H. H. Curtiss" relates to a similar device.

Various commercial methods have been proposed for copying directly upon bromide paper without the intermediary of a negative.

A number of years ago there was introduced a commercial bromide paper copying machine known as the "Record Camera," which was equipped with a 222.

1 "Use of Photography in Data Collections," Elec. World, 28 (1896),

2 "Photographing Rare Books and Manuscripts in Libraries," Bull. de la Soc. Frane. de Phot., [2] 25 (1909), 396.

${ }^{3}$ E. E. Fournier d'Albe, "On Photography by Reflection under Contact," Sci. Proc. Roy. Dublin Soc," (New Series) 12 (1909), 97; G. de Fontenay; "Cataphotography; Reproduction of Documents by Reflection," Compt. rend., 152 (1911), 1055, 1298.

" "Photogenic Copying Apparatus," U. S. Patent 1,251,076 (Dec. 25 1917); Offi. Gaz. U. S. Pat. Office, 245 (1917), 894.

- "Method and Apparatus for Photography," U. S. Patent 1,007,120 (May 19, 1914); Offi. Gaz. U. S. Pat: Office, 202 (1914); 745.

" "Making Photographic Copies without a Negative," Am. Machinist, [1] 31 (1908); 781; Elastman's "Record Camera." 